\title{
Mutations in the human $\alpha$-tectorin gene cause autosomal dominant non-syndromic hearing impairment
}

Kristien Verhoeven et al.

Nature Genet. 19, 60-62 (1998).

The nucleotide numbering of the mouse gene was used for the human DFNA12 and DFNA8 mutations. Because this numbering includes the 266-bp 5' untranslated region of the gene encoding mouse $\alpha$-tectorin, the numbering is off by 266 bp. Therefore, $5725 \mathrm{C} \rightarrow \mathrm{T}$ should be replaced by $5459 \mathrm{C} \rightarrow \mathrm{T}, 5738 \mathrm{G} \rightarrow \mathrm{A}$ by $5472 \mathrm{G} \rightarrow \mathrm{A}$ and $5876 \mathrm{~A} \rightarrow \mathrm{G}$ by $5610 \mathrm{~A} \rightarrow \mathrm{G}$. Because the numbering of amino acids was correct, this does not affect the conclusions drawn. 